\title{
Utjecaj načina obrade tla na prinos i energetsku učinkovitost proizvodnje uljane repice
}

\begin{abstract}
Sažetak
Budući da se osnovna obrada i priprema tla za sjetvu uljane repice obavljaju u sušnom razdoblju godine, vrlo je važno odabrati pravilan način obrade tla za svako područje, odnosno tip tla. Cilj ovog istraživanja bio je utvrditi utjecaj načina obrade tla na prinos i energetsku učinkovitost proizvodnje uljane repice u agroekološkim uvjetima Podravine. $U$ istraživanje su bile uključene dvije varijante obrade tla za uljanu repicu: 1) konvencionalna obrada - plug, integrirani agregat rotodrljača + sijačica; 2) reducirana obrada rovilo, integrirani agregat rotodrljača + sijačica. Istraživanje je provedeno na lesiviranom tlu na pijescima kod naselja Dinjevac u Podravini tijekom 2017./2018. godine na parceli ukupne površine 3,5 ha. Na jednoj polovici parcele $(1,75 \mathrm{ha}$ ) obavljena je konvencionalna obrada tla, a na drugoj polovici $(1,75 \mathrm{ha})$ reducirana obrada tla. Za sve radne operacije obrade tla korišten je traktor Fendt 716 Vario snage motora $118 \mathrm{~kW} \mathrm{~s}$ pogonom na sva četiri kotača. Prilikom svih radnih operacija mjerena je potrošnja goriva volumetrijskom metodom te je izračunat utrošak energije. Na svakoj varijanti obrade tla utvrđen je prinos u tri ponavljanja. Način obrade tla nije imao značajan utjecaj na prinos sjemena, udio ulja u sjemenu i prinos ulja. Reduciranom obradom tla ostvarena je ušteda energije od $387 \mathrm{MJ} \mathrm{ha}^{-1}$, odnosno smanjen utrošak goriva za $10 \mathrm{I} \mathrm{ha}^{-1}$. Stoga je reducirani način obrade tla ekološki prihvatljiviji zbog manje emisije CO2. Reducirana obrada je isplativija is ekonomskog stajališta jer je u usporedbi s konvencionalnom, ostvaren veći prihod za 282,00 kn ha ${ }^{-1}$, odnosno 3,42\%.
\end{abstract}

Ključne riječi: uljana repica, obrada tla, energija, troškovi, prinos

\section{Uvod}

Osnovni cilj obrade i pripreme tla za sjetvu svake ratarske kulture, a osobito sitnosjemene uljarice kao što je uljana repica je stvoriti idealan profil tla za sjetvu. O vremenu i načinu izvođenja osnovne obrade i pripreme tla za sjetvu uljane repice u velikoj mjeri ovisi nicanje, ostvarivanje poželjnih i ujednačenih sklopova za svaki pojedini hibrid te brz i snažan početni porast, što su osnovne pretpostavke uspješne proizvodnje. Uz pravilnu agrotehniku i sortiment u Hrvatskoj se može postići prinos i do 5,0 t ha ${ }^{-1}$. No za veliki broj proizvođača ovakav prinos je još nedostižan. Kako bi ostvarili visoki prinos, a ujedno što više smanjili troškove proizvodnje, mnogi proizvođači počinju primjenjivati razne sustave reducirane i/ili konzervacijske obrade tla. Po uzoru na današnje trendove u obradi tla teži se sa što manje prohoda postići odgovarajuću pripremu tla za sjetvu. Imajući u vidu da se sjetva uljane repice obavlja u sušnom dijelu godine, obrada tla predstavlja veliki izazov. Nerijetko se događa da je tlo toliko suho da se ne može obaviti pravovremeno i kvalitetno oranje. $U$ tom slučaju se kao alternativno rješenje nameće konzervacijska obrada tla u kojoj nema klasičnog oranja. Energetski gledano, na ovaj način se mogu postići odgovarajuće uštede, ali je potrebna viša razina znanja o odnosu obrada - tlo - biljka te suvremena mehanizacija (Pospišil, 2013). Ovakav sustav nije idealan jer se mogu pojaviti problemi s korovima, puževima, razgradnjom slame, slabijim početnim porastom, itd. Dosadašnja istraživanja su pokazala da se reduciranom obradom tla tj. primjenom rovila, integriranog agregata zvrk drljača + sijačica postiže najveća ekonomičnost, ušteda energije i radnog vremena u proizvodnji ozime pšenice i uljane repice (Grubor i sur., 2015). Birkas i sur.

1 JosipSpitek, mag.ing.agr.,AlejaAntunaAugustinčića16/I,10000Zagreb

2 prof.dr.sc. Milan Pospišil, doc.dr.sc. Igor Kovačev, doc.dr.sc. Igor Bogunović,

Sveučilište u Zagrebu Agronomski fakultet, Svetošimunska cesta 25, 10000 Zagreb,

Autor za korespondenciju: e-mail: mpospisil@agr.hr 
(2014). navode da je kod uljane repice zbog plitke sjetve važno radnim operacijama osigurati zadržavanje vlage u tlu nakon žetve predkulture.

Uzevši u obzir navedene činjenice, cilj ovog istraživanja bio je utvrditi utjecaj konvencionalne i reducirane obrade tla na prinos i energetsku učinkovitost proizvodnje uljane repice $u$ agroekološkim uvjetima Podravine.

\section{Materijal i metode}

Istraživanje je provedeno na lesiviranom tlu na pijesku (luvisol) kod naselja Dinjevac u Podravini (45o 57' 34" S, 17o 10' 34" I) tijekom 2017./2018. godine. U istraživanje su bile uključene dvije varijante obrade tla za uljanu repicu: 1) Konvencionalna obrada - plug, integrirani agregat rotodrljača + sijačica; 2) Reducirana obrada - rovilo, integrirani agregat rotodrljača + sijačica. Na jednoj polovici parcele (1,75 ha) je obavljena konvencionalna obrada tla, a na drugoj polovici $(1,75 \mathrm{ha})$ reducirana obrada tla. Za sve radne operacije obrade tla korišten je traktor Fendt 716 Vario snage motora $118 \mathrm{~kW}$ s pogonom na sva četiri kotača. Prilikom svih radnih operacija mjerena je potrošnja goriva volumetrijskom metodom, a zatim je izračunat utrošak energije na osnovi energetskog ekvivalenta dizel goriva od 38,7 $\mathrm{MJ} \mathrm{I}^{-1}$ (Cervinka, 1980). U pokusu je primijenjena uobičajena tehnologija proizvodnje uljane repice za ovo područje. Predkultura uljanoj repici bila je ozima pšenica. Nakon žetve pšenice obavljeno je prašenje strništa (15. 7. 2017.) plošnim kultivatorom na $10 \mathrm{~cm}$ dubine. U prvoj varijanti oranje je obavljeno 15. 8. 2017. četverobraznim plugom premetnjakom Lemken, tip Vari-opal 120 na dubinu od $30 \mathrm{~cm}$ (Slika 1). Radni zahvat pluga je $205 \mathrm{~cm}$, brzina oranja $7 \mathrm{~km} \mathrm{~h}^{-1}$, odnosno ostvareni učinak 1,22 ha $\mathrm{h}^{-1}$. U drugoj varijanti, umjesto oranja obavljeno je podrivanje s rovilom Strojometal na dubinu od 40 $-45 \mathrm{~cm}$ (Slika 2). Radni zahvat rovila je $210 \mathrm{~cm}$, brzina podrivanja $8 \mathrm{~km} \mathrm{~h}^{-1}$, odnosno ostvareni učinak 1,43 ha $^{-1}$.
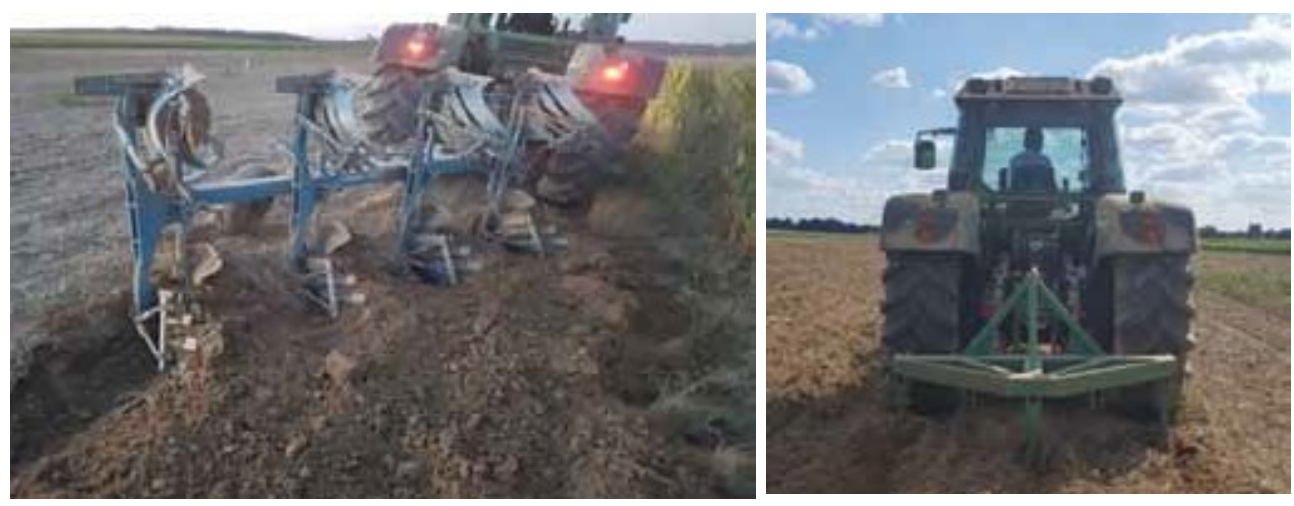

Slika 1. Oranje (snimila S. Spitek)

Figure 1. Ploughing (photo S. Spitek)
Slika 2. Podrivanje (snimila S. Spitek)

Figure 2. Chiselling (photo S. Spitek)

Osnovna gnojidba obavljena je s $200 \mathrm{~kg} \mathrm{ha}^{-1}$ mineralnog gnojiva NPK 7:20:30 u dva navrata. Dvije trećine ovog gnojiva (133 $\mathrm{kg} \mathrm{ha}^{-1}$ ) primijenjeno je prije oranja/podrivanja, a jedna trećina (67 kg ha-1) neposredno prije sjetve. Prva prihrana uljane repice obavljena je 15. 3. 2018. neposredno prije kretanja vegetacije u proljeće s $230 \mathrm{~kg} \mathrm{ha}^{-1} \mathrm{KAN}-\mathrm{a}$, a druga 27. 3. 2018. sa $180 \mathrm{~kg}$ $\mathrm{ha}^{-1} \mathrm{KAN}-\mathrm{a}$. Ukupno je primijenjeno $124,7 \mathrm{~kg} \mathrm{ha}^{-1} \mathrm{~N}, 40 \mathrm{~kg} \mathrm{ha}^{-1} \mathrm{P} \mathrm{O}_{5}$ i $60 \mathrm{~kg} \mathrm{ha}^{-1} \mathrm{~K}_{2} \mathrm{O}$. Za sjetvu je korišten hibrid Gordon sjemenske kuće KWS. Gustoća sjetve iznosila je 50 klijavih sjemenki $\mathrm{m}^{-2}$. Predsjetvena priprema tla i sjetva obavljene su 1. 9. 2017. u jednom prohodu sjetvenom linijom Amazone (integrirani agregat rotodrljača Amazone, tip KG 302 + sijačica Amazone, tip D9 3000 Special). Zaštita usjeva od korova obavljena je 3. 9. 2017. preparatom Teridox (dimetaklor 500 
$\left.\mathrm{g}^{-1}\right)$ u količini od 2,0 I ha ${ }^{-1}$. Za suzbijanje repičinog sjajnika korišten je preparat Karate Zeon (lambda cihalotrin $50 \mathrm{~g} \mathrm{I}^{-1}$ ) u dozi od $0,15 \mathrm{I} \mathrm{ha}^{-1}$. Žetva je obavljena 20. 6. 2018. žitnim kombajnom "Deutz - Fahr M 3580 H" sa žetvenim uređajem za uljanu repicu (produženi stol i dvije vertikalne kose razdjeljivači otkosa). Na svakoj varijanti obrade tla određen je sklop (biljaka $\mathrm{m}^{-2}$ ) i prinos uljane repice $u$ tri ponavljanja. Površina obračunske parcele u žetvi iznosila je 420 $\mathrm{m}^{2}$ (4,2 m zahvat kombajna x $100 \mathrm{~m}$ dužine). Nakon vaganja, prinos sjemena preračunat je u $\mathrm{t}$ ha $^{-1}$ na bazi $9 \%$ vlage $+2 \%$ nečistoća (Pospišil i Pospišil, 2013). Udio ulja u sjemenu određen je u n-heksanskom ekstraktu (HRN EN ISO 659:2010) u laboratoriju za tehnologiju ulja i masti Prehrambeno-biotehnološkog fakulteta Sveučilišta u Zagrebu. Prinos ulja je preračunat na apsolutno suhu tvar. Rezultati pokusa statistički su obrađeni računalnim programom SAS (SAS Institute, 2002). Značajnost razlika između istraživanih parametara utvrđena je t-testom na razini vjerojatnosti $p=0,05$.

\section{Vremenskeprilike}

Srednje mjesečne temperature zraka i mjesečne količine oborina tijekom vegetacije uljane repice u 2017./2018. godini i višegodišnji prosjek za meteorološku postaju Đurđevac prikazane su u Tablici 1. Tijekom vegetacije uljane repice u 2017./2018. godini prosječna srednja mjesečna temperatura zraka bila je viša u odnosu na višegodišnji prosjek za 0,5 o C. Osobito visoke srednje dnevne temperature zraka zabilježene su u kolovozu i siječnju. Unatoč činjenici da je tijekom vegetacije uljane repice u 2017./2018. godini palo dovoljno oborina ( $895 \mathrm{~mm}$ ), njihov raspored nije bio idealan. Nedostatak oborina je zabilježen u kolovozu $(18,7 \mathrm{~mm})$ i svibnju (32,5 mm). Iz priloženih podataka razvidno je da je kolovoz 2017. bio suh i topao te tlo nije bilo pogodno za obradu. Na smanjenje prinosa značajan utjecaj imao je nedostatak oborina u svibnju kad je uljana repica završavala cvatnju i prelazila u fazu nalijevanja sjemena. Veća količina oborina uz variranje temperature zraka u fazi zriobe utjecale su na pucanje komuški i osipanje sjemena.

Tablica 1. Srednje mjesečne temperature zraka i mjesečne količine oborina tijekom vegetacije uljane repice i višegodišnji prosjek za meteorološku postaju Đurđevac

Table 1. Mean monthly air temperature and total month precipitation during the rapeseed growing season and long-term average for meteorological station Đurđevac

\begin{tabular}{|c|c|c|c|c|}
\hline \multirow[t]{3}{*}{ Mjesec / Month } & \multicolumn{2}{|c|}{$\begin{array}{l}\text { Srednje mjesečne temperature zraka, 으 } \\
\text { Mean monthly air temperature, 으 }\end{array}$} & \multicolumn{2}{|c|}{$\begin{array}{l}\text { Mjesečne količine oborina, } \mathrm{mm} \\
\text { Total month precipitation, } \mathrm{mm}\end{array}$} \\
\hline & 2017./2018. & Prosjek/Average & & Prosjek/Average \\
\hline & & $2009-2018$ & 2017./2018. & 2009.-2018. \\
\hline Kolovoz / August & 22,3 & 20,9 & 18,7 & 62,6 \\
\hline Rujan / September & 15,4 & 16,2 & 153,9 & 109,9 \\
\hline Listopad / October & 11,3 & 10,8 & 92,2 & 80,7 \\
\hline Studeni / November & 6,7 & 6,7 & 74,1 & 69,1 \\
\hline Prosinac / December & 3,8 & 2,0 & 105,8 & 58,9 \\
\hline Siječanj / January & 4,9 & 1,0 & 44,6 & 66,3 \\
\hline Veljača / February & $-0,8$ & 2,0 & 132,6 & 74,6 \\
\hline Ožujak / March & 4,5 & 6,8 & 93,6 & 48,8 \\
\hline Travanj / April & 14,9 & 12,4 & 51,4 & 43,5 \\
\hline Svibanj / May & 18,8 & 16,4 & 32,5 & 92,7 \\
\hline Lipanj / June & 19,6 & 20,0 & 95,6 & 87,4 \\
\hline Prosjek / Average & 11,0 & 10,5 & - & - \\
\hline Ukupno / Total & - & - & 895,0 & 789,7 \\
\hline
\end{tabular}

Izvor: Državni hidrometeorološki zavod, 2019./Source: Croatian Meteorological and Hydrological Service, 2019 


\section{Rezultati i rasprava}

Prosječni sklop uljane repice u žetvi iznosio je 42 biljke $\mathrm{m}^{-2}$. Variranje ostvarenog sklopa u žetvi nije bilo značajno, a kretalo se u granicama od $\pm 5 \%$ unutar svake varijante. T-testom je utvrđeno da nema značajne razlike između istraživanih varijanti obrade tla u prinosu sjemena, udjelu ulja i prinosu ulja (Tablica 2). Reduciranom obradom tla ostvaren je za 0,125 t ha-1 ili 3,43 \% veći prinos sjemena u odnosu na konvencionalnu obradu. $U$ istraživanjima Bonari i sur. (1995) način obrade tla također nije imao značajan utjecaj na prinos sjemena i biomase uljane repice.

Tablica 2. Utjecaj načina obrade tla na prinos sjemena, udio ulja i prinos ulja uljane repice (srednja vrijednost \pm standardna devijacija)

Table 2. Impact of soil tillage system on seed yield, oil content and oil yield of rapeseed (Mean \pm St.Dev.)

\begin{tabular}{cccc}
\hline Varijanta / Treatments & $\begin{array}{c}\text { Prinos sjemena } \\
\text { Seed yield } \\
\mathrm{t} \mathrm{ha}^{-1}\end{array}$ & $\begin{array}{c}\text { Udio ulja } \\
\text { Oil content } \\
\text { \% na s.t. / \% on d.m. }\end{array}$ & $\begin{array}{c}\text { Prinos ulja } \\
\text { Oil yield } \\
\mathrm{t} \mathrm{ha}^{-1}\end{array}$ \\
\hline $\begin{array}{c}\text { Konvencionalna obrada tla } \\
\text { Conventionaltillage }\end{array}$ & $3,505 \pm 0,182$ & $46,23 \pm 0,481$ & $1,442 \pm 0,090$ \\
\hline $\begin{array}{c}\text { Reducirana obradatla } \\
\text { Reducedtillage }\end{array}$ & $3,630 \pm 0,274$ & $45,79 \pm 0,595$ & $1,478 \pm 0,093$ \\
\hline p-vrijednost & 0,5469 n.s. & 0,3757 n.s. & 0,6535 n.s. \\
\hline
\end{tabular}

n.s. - nije signifikantno / not significant

Reducirani način obrade tla pokazao je manji utrošak goriva (31 I ha $\left.{ }^{-1}\right)$ i energije $(1199,7$ MJ ha-1) u odnosu na konvencionalni (Tablica 3). Najviše goriva/energije utrošeno je za oranje $(53,6 \%)$, odnosno podrivanje $(38,7 \%)$. Zimmer i sur. (2014) navode da je najveća energetska rezerva u poljoprivredi racionalizacija pojedinih elemenata proizvodnje. $U$ ratarstvu je to npr. izostavljanje oranja, jer je ispitivanjima dokazano da se bez oranja (koje troši 25 do $35 \mathrm{~kg} \mathrm{ha}^{-1}$ dizel goriva, što je polovica ukupne potrebe za rad u polju) može ne samo održavati visoki prinos, već i povećati. U istraživanjima Kovačev i sur. (2016) zamjena pluga s rovilom u primarnoj obradi tla rezultirala je znatno nižim utroškom goriva u odnosu na konvencionalnu obradu, od $17 \%$ u pripremi tla za uljanu repicu do $30 \%$ za ozimi ječam.

Tablica 3. Utrošak goriva i energije prilikom konvencionalne i reducirane obrade tla

Table 3. Fuel and energy consumption in conventional and reduced tillage systems

\begin{tabular}{|c|c|c|c|c|c|}
\hline \multicolumn{3}{|c|}{ Konvencionalna obrada tla / Conventional tillage } & \multicolumn{3}{|c|}{ Reducirana obrada tla / Reduced tillage } \\
\hline $\begin{array}{l}\text { Radna operacija/ } \\
\text { Field operation }\end{array}$ & $\begin{array}{c}\text { Utrošakgoriva } \\
\text { Fuel } \\
\text { I ha }^{-1}\end{array}$ & $\begin{array}{c}\text { Utrošak energije } \\
\text { Energy } \\
\text { consumption MJ } \\
\text { ha }^{-1}\end{array}$ & $\begin{array}{l}\text { Radna operacija/ } \\
\text { Field operation }\end{array}$ & $\begin{array}{c}\text { Utrošakgoriva } \\
\text { Fuel } \\
\text { I ha }^{-1}\end{array}$ & $\begin{array}{c}\text { Utrošak energije } \\
\text { Energy } \\
\text { consumption MJ } \\
\text { ha }^{-1}\end{array}$ \\
\hline $\begin{array}{l}\text { Prašenje strništa / } \\
\text { Stubble cleaning }\end{array}$ & 9 & 348,3 & $\begin{array}{l}\text { Prašenje strništa / } \\
\text { Stubble cleaning }\end{array}$ & 9 & 348,3 \\
\hline $\begin{array}{c}\text { Oranje / } \\
\text { Ploughing }\end{array}$ & 22 & 851,4 & $\begin{array}{l}\text { Podrivanje / } \\
\text { Chiselling }\end{array}$ & 12 & 464,4 \\
\hline Sjetva / Sowing & 10 & 387,0 & Sjetva / Sowing & 10 & 387,0 \\
\hline Ukupno / Total & 41 & 1586,7 & Ukupno / Total & 31 & 1199,7 \\
\hline
\end{tabular}


Ukupni prihodi u proizvodnji uljane repice izračunati su prema prosječnom prinosu sjemena za svaku varijantu pokusa i prosječnu otkupnu cijenu u vrijeme žetve $\left(2,35 \mathrm{kn} \mathrm{kg}^{-1}\right)$. Ukupni troškovi uključuju troškove goriva (plavi dizel $=5,49 \mathrm{kn} \mathrm{l}^{-1}$ ) kod svake varijante obrade tla. Ostali troškovi ovdje nisu uračunati jer su isti za obje varijante. Kod reducirane obrade tla manji su troškovi goriva za $24 \%$ u odnosu na konvencionalnu obradu tla (Tablica 4). Reduciranom obradom tla ostvaren je veći prihod $\left(8.530,50 \mathrm{kn} \mathrm{ha}^{-1}\right)$ u odnosu na konvencionalnu obradu tla $\left(8.248,50 \mathrm{kn} \mathrm{ha}^{-1}\right)$. Navedeni podaci ukazuju da je reducirani način obrade tla s ekonomskog stajališta isplativiji jer su u usporedbi s konvencionalnim troškovi goriva manji za 54,90 kn ha-1, a ukupni prihod veći za 282,00 kn ha-1. Dakle, zamjena operacije oranja (konvencionalna obrada tla) operacijom podrivanja (reducirana obrada tla) na istraživanom području rezultirala je većim prihodom za $282,00 \mathrm{kn} \mathrm{ha}^{-1}$, odnosno $3,42 \%$.

Tablica 4. Troškovi utrošenog goriva i ostvareni prihod

Table 4. Fuel costs and generated income

\begin{tabular}{ccc}
\hline Varijanta / Treatments & Troškovi goriva / Fuel costs kn ha ${ }^{-1}$ & Prihod / Income kn ha ${ }^{-1}$ \\
\hline $\begin{array}{c}\text { Konvencionalna obrada tla } \\
\text { Conventional tillage }\end{array}$ & 225,09 & $8.248,50$ \\
\hline $\begin{array}{c}\text { Reducirana obrada tla } \\
\text { Reduced tillage }\end{array}$ & 170,19 & $8.530,50$ \\
\hline Razlika / Difference & 54,90 & 282,00 \\
\hline
\end{tabular}

Kovačev i sur. (2016) također navode da prosječni prinosi u nekonvencionalnim sustavima nisu bili umanjeni smanjenjem obrade tla što bi značilo da nekonvencionalni sustavi obrade nisu slabiji od konvencionalne obrade i mogu biti važan alat za poboljšanje energetske učinkovitosti i produktivnosti u proizvodnji uljane repice i ozimog ječma. Mustapić i Hrust (1988) navode da su prednosti obrade tla rovilom povećanje ukupnog stupnja mrvljenja tla, a time i poboljšanje aeracije i filtracije u tlu, poboljšava se vodozračni odnos u tlu, povećava se vodopropusnost i akumulacija oborinske vode u dubljim slojevima i značajna je ušteda energije po jedinici obradive površine. lako ovim istraživanjem nisu praćena svojstva tla, u nekoliko istraživanja utvrđen je veći sadržaj organske tvari, povoljnija struktura tla i manja zbijenost tijekom vegetacijske sezone nakon obrade rovilom u odnosu na oranje (Alvarez i Steinbach, 2009; Bogunović i sur., 2019) što može biti razlog povećanja prinosa test kultura.

\section{Zaključak}

$\mathrm{Na}$ temelju jednogodišnjih istraživanja utjecaja načina obrade tla na prinos i energetsku učinkovitost proizvodnje uljane repice u agroekološkim uvjetima Podravine mogu se donijeti slijedeći zaključci:

- način obrade tla nije imao značajan utjecaj na prinos sjemena, udio ulja i prinos ulja po

hektaru;

- reduciranom obradom tla (rovilo, integrirani agregat rotodrljača + sijačica) smanjen je utrošak goriva za $10 \mathrm{I} \mathrm{ha}^{-1}$, odnosno ostvarena je ušteda energije od $387 \mathrm{MJ} \mathrm{ha}^{-1}$;

- s ekonomskog stajališta isplativiji je reducirani način obrade tla jer je u usporedbi s konvencionalnim (plug, integrirani agregat rotodrljača + sijačica) ostvaren veći prihod za 282,00 $\mathrm{knha}^{-1}$, odnosno $3,42 \%$. 


\title{
Literatura
}

Alvarez, R., Steinbach, H. S. (2009) A review of the effects of tillage systems on some soil physical properties, water content, nitrate availability and crops yield in the Argentine Pampas. Soil and Tillage Research, 104(1), 1-15.

Birkas, M., Jug, D., Kisić, I. (2014) Book of Soil Tillage. Szent Istvan University Press. Gödöllő

Bogunović, I., Kovacs, P. G., Dekemati, I., Kisić, I., Balla, I., Birkas, M. (2019) Long-term effect of soil conservation tillage on soil water content, penetration resistance, crumb ratio and crusted area. Plant, Soil and Environment, 65(9), 442-448.

Bonari, E., Mazzoncini, M., Peruzzi, A. (1995) Effects of conventional and minimum tillage on winter oilseed rape (Brassica napus L.) in a sandy soil. Soil and Tillage Research, 33 (2), 91-108.

Cervinka, V. (1980) Fuel and energy efficiency. Handbook of energy utilization in agriculture. Pimentel, D. (Ed), Boca Raton, USA

Grubor, M., Maletić, I., Lakić, J., Kovačev, I., Košutić, S. (2015) Ekonomičnost proizvodnje pšenice i uljane repice s različitim sustavima obrade tla. In: Proceedings of the $43^{\text {th }}$ International Symposium on Agricultural Engineering, Actual Tasks on Agricultural Engineering, Opatija, Hrvatska, str. 265-274.

HRN EN ISO 659:2010 Uljarice - određivanje udjela ulja (Referentna metoda). Internacionalni standard. Hrvatski zavod za norme, Zagreb, Hrvatska

Kovačev, I., Čopec, K., Fabijanić, G., Košutić, S., Filipović, D. (2016) Energy and labour efficiency of tillage systems in oilseed rape and barley production. In: Proceedings of the $44^{\text {th }}$ International Symposium on Agricultural Engineering, Actual Tasks on Agricultural Engineering, Opatija, Hrvatska, str. 195-203.

Mustapić, Z., Hrust, V. (1988) Utjecaj suvremenih agrotehničkih mjera na uspješnu proizvodnju uljane repice. Agrohemija 2: 141-148.

Pospišil, A., Pospišil, M. (2013) Ratarstvo - praktikum. Sveučilište u Zagrebu Agronomski fakultet, Zagreb

Pospišil, M. (2013). Ratarstvo II. dio - industrijsko bilje, Zrinski, Čakovec

SAS Institute (2002) SAS/STAT User's guide. Ver. 9.1, SAS Inst., Cary, NC, USA Osijek

Zimmer, R., Košutić, S., Kovačev, I., Zimmer, D. (2014) Integralna tehnika obrade tla i sjetve. Poljoprivredni fakultet,

\section{Napomena}

Ovaj rad je izvod iz diplomskog rada obranjenog 27. 09. 2019.

Prispjelo/Received:10.1.2020.

Prihvaćeno/Accepted: 6.4.2020.

\section{Professionalpaper}

\section{Impact of soil tillage on yield and energy efficiency of rapeseed production}

\begin{abstract}
Considering that primary tillage and soil preparation for the sowing of rapeseed is conducted during dry season, it is very important to choose the correct system of tillage for each area or soil type. This research aimed to determine the impact of soil tillage on yield and energy efficiency of rapeseed production under agro-ecological conditions of region Podravina. The study included two systems of tillage for rapeseed: 1) conventional tillage - mouldboard plough, rotary harrow integrated with seed drill; 2) reduced tillage chisel plough, rotary harrow integrated with seed drill. The study was carried out on leached soil on sands in year 2017/2018 on a plot with a total surface area of $3.5 \mathrm{ha}$. Conventional tillage was carried out on one half of the plot (1.75 ha), and reduced tillage on the other half (1.75 ha). Fendt 716 Vario $118 \mathrm{~kW}$, an allwheel-drive tractor, was used for all tillage operations. During all work operations, fuel consumption was measured by volumetric method and energy consumption was subsequently calculated. Yield was determined on each variant of tillage in three replications. The system of tillage did not have a significant effect on seed yield, oil content in seed and oil yield. Reduced tillage resulted in energy savings of $387 \mathrm{MJ} \mathrm{ha}^{-1}$, i.e. reduced fuel consumption by $10 \mathrm{I} \mathrm{ha}^{-1}$. Therefore, reduced tillage is more environmentally friendly due to lower $\mathrm{CO}_{2}$ emissions. From an economic point of view, a reduced cost of tillage is more profitable, as compared to conventional tillage, because a higher income of $282.00 \mathrm{kn} \mathrm{ha}^{-1}$, that is $3.42 \%$, has been achieved. Key words: rapeseed, tillage, energy, costs, yield
\end{abstract}

